\title{
Outcomes in patients undergoing complex cardiac repairs with cross clamp times over 300 minutes
}

\author{
Blake Shultz ${ }^{1,4^{*}}$, Tomasz Timek ${ }^{1}$, Alan T. Davis ${ }^{2,3}$, John Heiser ${ }^{1}$, Edward Murphy ${ }^{1}$, Charles Willekes ${ }^{1}$
} and Robert Hooker ${ }^{1}$

\begin{abstract}
Background: Long cross clamp times have been associated with poor clinical outcomes, yet some patients require extremely long ischemic times to repair complex surgical problems. The purpose of this study was to examine short and mid-term survival and to identify risk factors for mortality and morbidity in patients with cross clamp times greater than or equal to $300 \mathrm{~min}$.

Methods: Review of our institution's Society of Thoracic Surgeons database identified 202 patients who underwent surgical procedures necessitating aortic cross clamp times 300 min or greater between 2001 and 2012. Short-term (30-day) clinical outcomes were derived from this database and survival was assessed utilizing the Social Security Death Index. Univariate and multivariate analyses were used to determine the relationship between independent variables and mortality and postoperative outcomes.

Results: The average age of the patients was $69.5 \pm 10.6$ (mean \pm standard deviation) years and the mean ejection fraction was $52 \pm 12 \% .70 .3 \%$ of patients were male. Mean cross clamp time was $346 \pm 45 \mathrm{~min}$, and total bypass time was $421 \pm$ $70 \mathrm{~min}$. Thirty-day mortality was $12.4 \%$. The incidence of bleeding and stroke were $6.4 \%$ and $4.0 \%$ respectively. Prolonged ventilation occurred in $26.7 \%$ of patients, and incidence of renal failure was $10.4 \%$. One, three, five, and seven year survival of the patients who survived the first 30 days post-surgery was $91.9 \%, 83.2 \%, 75.6 \%$ and $65.7 \%$ respectively. Proportional hazards analysis determined that the statistically significant hazard ratios for mid-term mortality for female gender, age, and prolonged postoperative ventilation were $2.11,1.04$ and 2.72 , respectively ( $p<0.05$ for each).

Conclusions: Cardiac procedures requiring extremely long ischemic times have significant early mortality and morbidity. However, mid-term survival in the patients who survive is good. Decision-making regarding operability in complex cases should allow for long ischemic times.
\end{abstract}

Keywords: Adult cardiac surgery, Cross-clamp time, Mortality, Morbidity

\section{Background}

Clinical studies have shown that aortic cross-clamp (XCL) time and cardiopulmonary bypass time $(\mathrm{CPB})$ during cardiac surgery are independent predictors of mortality and morbidity in postoperative patients $[1,2,4]$. Increasing $\mathrm{XCL}$ times are associated with low cardiac output, prolonged ventilation, renal compromise, and neurological

\footnotetext{
* Correspondence: blake.shultz@yale.edu

${ }^{1}$ Department of Thoracic and Cardiovascular Surgery, Spectrum Health, Fred and Lena Meijer Heart and Vascular Institute, 100 Michigan St. NE, 49503 Grand Rapids, MI, USA

${ }^{4} 123$ York Street Apt. \#22V, New Haven, CT 06511, USA

Full list of author information is available at the end of the article
}

deficit immediately following surgery [1-5]. With the various adverse effects associated with long XCL times, midterm survival after complex surgeries has historically had a poor prognosis. A study by Al-Sarraf et al. showed that in-hospital mortality was significantly higher for patients with XCL times greater than 90 min than for patients with XCL times $>60 \leq 90$ min [1]. Furthermore, the in-hospital mortality within the latter group was significantly higher than that of patients with XCL times $\leq 60 \mathrm{~min}$.

There are no large reports in the literature regarding the effects of XCL times greater than 300 min and few studies that examine mid-term survival as a function of XCL time. 
A large study by Doenst et al. examined data from 28,684 patients but excluded data from patients with XCL times over 120 min [4]. A study by Nissinen et al. examined 30day mortality as a function of XCL time, but only included data from 30 patients with XCL times greater than $300 \mathrm{~min}$ [2]. Therefore, our study retrospectively examined clinical outcomes in a cohort of patients undergoing complex cardiac procedures with cross clamp times exceeding $300 \mathrm{~min}$.

\section{Methods}

\section{Data source}

This study includes data collected from an analysis of our institution's prospectively collected Society of Thoracic Surgeons (STS) database. All patients with primary cross clamp times over $300 \mathrm{~min}$ within the last 14 years were reviewed. Patients excluded included those who required a second cross clamp, any patients that had a ventricular assist device inserted and those with additional ischemic time for further repair. A total of 202 patients were identified who underwent complex surgical procedures necessitating single aortic cross clamp time 300 min or greater between 2001 and 2012. 113 patients were seen from 2001-2006 and 89 patients from 2007-2012. Our practice operates within a large, tertiary institution and saw approximately 900 patients per year until 2010 and 1,000 patients per year thereafter.

Pre-, intra-, and postoperative variables were gathered on all patients. Operative notes were obtained for data regarding the type of surgery. Short-term (30-day) clinical outcomes were derived from our STS database. Mid-term survival data $(<14$ years) of patients who survived the initial surgery was derived from the Social Security Death Index [23].

\section{Cardiopulmonary bypass}

All surgeries were performed using generalized, standard anesthesia. Following a median sternotomy, a heparin dose of $350 \mathrm{IU} / \mathrm{kg}$ was given to maintain an activated clotting time of 400-600 s. Cannulation was accomplished as per the normal institutional protocol. A membrane oxygenator and roller pump system was used along with a heparin coated tubing set. 10,000 IU heparin and $1,400 \mathrm{~mL}$ Hartmann's solution was used to prime the extracorporeal circuit. On average, the patients were cooled to $32{ }^{\circ} \mathrm{C}$. Myocardial protection was accomplished with antegrade and retrograde cold blood cardioplegia in a 4:1 solution. Cardioplegia was delivered every $15 \mathrm{~min}$ and titrated to maintain distal septal temperature of less than $10^{\circ}$ Celsius. A warm retrograde shot was given before clamp removal. Surgeries were performed with one aortic cross clamp. Both cardiotomy suction and cell saver were used, with cell saver used primarily for blood shed into the pericardium. Milrinone and levophed were used in the majority of patients to wean from bypass.

\section{Statistical Analysis}

Categorical data are expressed as percentages and quantitative variables are reported as the mean \pm standard deviation (SD). The $x^{2}$ test and the Fisher's Exact Test were used for the univariate analyses of categorical data and the unpaired $\mathrm{t}$-test for was used for the univariate analysis of continuous data. A Kaplan-Meier survival curve was constructed from patient mortality data for those patients surviving more than 30 days postoperatively. Two logistic regression analyses were performed, using the 30-day outcomes of either mortality or complications as the dependent variables. For these analyses, independent variables tested included patient age, gender, perfusion time, cross clamp time, surgery type (whether or not the procedure included a coronary artery bypass graft (CABG)), and era (surgery performed from 2001-2006 vs. 2007-2012).

Univariate and multivariate analyses with respect to complications included eight 30-day postoperative complications. These complications are stroke, renal failure, perioperative myocardial infarction (MI), deep sternal infection, ventilation time $>48 \mathrm{~h}$, atrial fibrillation, bleeding requiring reoperation and pneumonia. Stroke was defined as a confirmed neurological deficit of abrupt onset that does not resolve in $24 \mathrm{~h}$. Renal failure was defined as an increase in creatinine 3.0 times over baseline, or as any requirement for dialysis. Perioperative MI was defined as new Q waves on ECG or troponin levels over 30. Deep sternal infection was defined as all of the following: (i.) wound opened with incision and drainage or any reexploration, (ii.) positive wound cultures and (iii.) treatment with antibiotics beyond perioperative prophylaxis. Ventilation time $>48$ was defined as any prolonged postoperative mechanical ventilation over $48 \mathrm{~h}$. Finally, pneumonia was defined as the presence of lung infiltrate and pathogenic sputum culture, and placement on antibiotics for pneumonia.

A Cox proportional hazards analysis was performed, using mid-term mortality (occurring more than 30 days and $<14$ years following the surgical procedure) as the dependent variable. The independent variables used included patient age, gender, perfusion time, cross clamp time, surgery type, era, and ventilation time $>48 \mathrm{~h}$. Significance was assessed at $p<0.05$. IBM SPSS Statistics version 22.0 (Armonk, NY, USA) was used to perform the statistical analyses.

\section{Results}

Preoperative clinical characteristics and patient demographics are summarized in Table 1. Patients ranged in age from 35 to 89 years. The majority of the patients were males, and less than $5 \%$ of the cases were emergent. Only $10.4 \%$ 
Table 1 Preoperative characteristics $(n=202)$

\begin{tabular}{|c|c|}
\hline Variable & No. (\%) \\
\hline $\begin{array}{l}\text { Patient Age }(y)^{a} \\
\text { a }\end{array}$ & $69.5 \pm 10.6$ \\
\hline Gender (males, \%) & $142(70.3 \%)$ \\
\hline \multicolumn{2}{|l|}{ Preoperative status } \\
\hline Elective & $138(68.3 \%)$ \\
\hline Urgent & $55(27.2 \%)$ \\
\hline Emergent/salvage & $9(4.5 \%)$ \\
\hline \multicolumn{2}{|l|}{ Incidence } \\
\hline Reoperation & $32(15.8 \%)$ \\
\hline \multicolumn{2}{|l|}{ First operation } \\
\hline IABP - Preoperative & $170(84.2 \%)$ \\
\hline \multicolumn{2}{|l|}{$6(3.0 \%)$} \\
\hline Smoker & $91(45.0 \%)$ \\
\hline \multicolumn{2}{|l|}{ Angina type } \\
\hline Unstable & $15(7.4 \%)$ \\
\hline Stable & 65 (32.2 \%) \\
\hline \multicolumn{2}{|l|}{ Time from MI to surgery } \\
\hline 1-7 days & $10(5.0 \%)$ \\
\hline 8-21 days & $11(5.4 \%)$ \\
\hline$>21$ days & $43(21.3 \%)$ \\
\hline \multicolumn{2}{|l|}{ NYHA class } \\
\hline$\leq 2$ & $41(24.7 \%)$ \\
\hline 3 and 4 & $125(75.3 \%)$ \\
\hline Diabetes & $64(31.7 \%)$ \\
\hline Ejection fraction $\leq 50 \%$ & 77 (39.5 \%) \\
\hline Ejection fraction (\%) ${ }^{a}$ & $52.0 \pm 12.0$ \\
\hline
\end{tabular}

IABP intra-aortic balloon pump, MI myocardial infarction, NYHA New York Heart Association

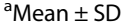

of the patients were operated on within 21 days of myocardial infarction. Over three-quarters of the patients were New York Heart Association (NYHA) class III and IV (75.3\%).

Table 2 presents operative data for the patient group. The majority of patients $(77.3 \%)$ underwent valve repair or replacement procedures with CABG. Mitral valve repair involved $59.5 \%$ of the surgeries, $72.4 \%$ involved aortic valve replacement and $16.4 \%$ involved tricuspid repair. There were two isolated mitral valves in patients with severe mitral annular calcification. Additionally, $15.8 \%$ of surgeries were reoperations. The isolated CABG procedures were all revisions with severe adhesions and patent grafts.

Intraoperative and postoperative data are presented in Table 3. The mean $\mathrm{CPB}$ and XCL times were both more than five hours. The most frequent postoperative complications were: atrial fibrillation, prolonged ventilation $>48 \mathrm{~h}$, renal failure, and pneumonia.
Table 2 Procedural characteristics and their distribution among patients within the sample $(n=202)^{a}$

\begin{tabular}{|c|c|}
\hline Variable & No. (\%) \\
\hline \multicolumn{2}{|l|}{ Mitral } \\
\hline+ other $^{1}$ & $3(1.5 \%)$ \\
\hline+ tricuspid + other $^{2}$ & $3(1.5 \%)$ \\
\hline Isolated & $2(1.0 \%)$ \\
\hline \multicolumn{2}{|l|}{ Aortic } \\
\hline + other ${ }^{3}$ & $13(6.4 \%)$ \\
\hline+ mitral & $10(5.0 \%)$ \\
\hline+ other $^{4}$ & $8(4.0 \%)$ \\
\hline+ tricuspid & $1(0.5 \%)$ \\
\hline Tricuspid + mitral + aortic + other ${ }^{5}$ & $6(3.0 \%)$ \\
\hline \multicolumn{2}{|l|}{ CABG } \\
\hline+ aortic & $40(19.8 \%)$ \\
\hline+ other $^{6}$ & $21(10.4 \%)$ \\
\hline + mitral & $13(6.4 \%)$ \\
\hline + other ${ }^{7}$ & $14(6.9 \%)$ \\
\hline $\begin{array}{l}+ \text { aortic }+ \text { mitral } \\
+ \text { other }^{8}\end{array}$ & $\begin{array}{l}21(10.4 \%) \\
17(8.4 \%)\end{array}$ \\
\hline + mitral + tricuspid & $2(1.0 \%)$ \\
\hline + other $^{9}$ & $12(5.9 \%)$ \\
\hline+ aortic + mitral + tricuspid + other ${ }^{10}$ & $9(4.5 \%)$ \\
\hline Isolated & $7(3.6 \%)$ \\
\hline
\end{tabular}

The results of univariate analyses with respect to patient death are shown in Table 4. The mortalities are presented as total mortalities ("all deaths"), mortalities within 30 days ("operative deaths"), and mortalities after 30 days (midterm deaths). Female gender, and increased age, perfusion time and cross clamp time, were significantly associated with increased overall death. Perfusion time, cross clamp time, era, ventilation $>48 \mathrm{~h}$, total ventilation time, total Intensive Care Unit (ICU) stay and length of hospital stay were significantly associated with increased mid-term death, while female gender and perfusion time were significantly associated with operative deaths.

Univariate analyses with respect to complications other than mortality are shown in Table 5 . Increased perfusion and cross clamp time were both associated with increased 30-day complications. Additionally, length of hospital stay, total ICU stay and ventilation $>48 \mathrm{~h}$ were also significantly related to increased complications.

Logistic regression analysis was performed using 30day mortality or 30-day complications as the dependent variables (Table 6). Female gender was the only independent variable that was significantly predictive of mortality. 
Table 3 Intraoperative characteristics, 30-day postoperative outcomes, and their distributions among the patients $(n=202)$

\begin{tabular}{|c|c|}
\hline Variable & No. (\%) \\
\hline \multicolumn{2}{|l|}{ Intraoperative } \\
\hline Procedure (\% CABG) & $156(77.2 \%)$ \\
\hline IABP & $12(5.9 \%)$ \\
\hline CPB time $(\min )^{a}$ & $421 \pm 70$ \\
\hline$X C L$ time $(\min )^{a}$ & $346 \pm 45$ \\
\hline \multicolumn{2}{|l|}{ IMA used } \\
\hline Left or Right IMA & 115/157 (73.2 \%) \\
\hline Both IMAs & 1/157 (0.6 \%) \\
\hline \multicolumn{2}{|l|}{ Postoperative } \\
\hline IABP & $5(2.5 \%)$ \\
\hline $\begin{array}{l}\text { Operative mortality } \\
\text { Perioperative MI }\end{array}$ & $\begin{array}{l}25(12.4 \%) \\
4(2.0 \%)\end{array}$ \\
\hline \multicolumn{2}{|l|}{ Postoperative ventilation } \\
\hline$\leq 48 \mathrm{~h}$ & $148(73.3 \%)$ \\
\hline$>48 \mathrm{~h}$ & $54(26.7 \%)$ \\
\hline Postoperative ventilation $(h)^{b}$ & $13.0(6.0-66.9)$ \\
\hline Deep sternal infection & $3(1.5 \%)$ \\
\hline Stroke & $8(4.0 \%)$ \\
\hline Atrial fibrillation & $53(26.2 \%)$ \\
\hline Pneumonia & $17(8.4 \%)$ \\
\hline Renal failure & $21(10.4 \%)$ \\
\hline Bleeding requiring reoperation & $13(6.4 \%)$ \\
\hline Intensive care unit readmission & $8(4.0 \%)$ \\
\hline Total intensive care unit stay $(h)^{b}$ & $96.0(43.0-212.3)$ \\
\hline Total hospital stay (days) ${ }^{\text {b }}$ & $11.0(7.0-20.5)$ \\
\hline
\end{tabular}

Females were 2.44 times more likely to die than males. None of the independent variables were statistically significant predictors of 30-day complications.

Cox proportional hazards analysis was also performed using mid-term mortality for patients who survived at least 30 days following the surgery as the dependent variable. Significant predictors of mortality included female gender, age, and ventilation $>48 \mathrm{~h}$ (Table 7).

A Kaplan-Meier survival curve is shown in Fig. 1 for patients who survived at least 30 days following surgeries with cross clamp times greater than $300 \mathrm{~min}$. One, three, five, and seven year survival was $91.9 \%, 83.2 \%, 75.6 \%$, and $65.7 \%$ respectively.

\section{Discussion}

Complex surgical procedures requiring long cross clamp times for complete repair are often patients' only chance for survival and better quality of life. Decisions about
Table 4 Univariate analysis of pre-, intra-, and postoperative variables with respect to patient mortality

\begin{tabular}{|c|c|c|c|}
\hline Variable & $\begin{array}{l}\text { All Deaths } \\
\text { p-value } \\
(n=72)\end{array}$ & $\begin{array}{l}\text { Mid-term } \\
\text { Deaths }{ }^{a} \\
p^{-v a l u e} \\
(n=47)\end{array}$ & $\begin{array}{l}\text { Operative } \\
\text { Deaths } \\
p \text {-value } \\
(n=25)\end{array}$ \\
\hline$\overline{E r a b}$ & 0.162 & 0.024 & 0.393 \\
\hline \multicolumn{4}{|l|}{ Preoperative } \\
\hline Gender & 0.001 & 0.066 & 0.009 \\
\hline Status ${ }^{c}$ & 0.186 & 0.691 & 0.157 \\
\hline Left main discharge $>50$ & 0.071 & 0.313 & 0.183 \\
\hline Patient Age & 0.015 & 0.066 & 0.322 \\
\hline Angina & 0.137 & 0.0497 & 0.699 \\
\hline Diabetes & 0.375 & 0.750 & 0.378 \\
\hline Smoker & 0.898 & 0.344 & 0.161 \\
\hline First operation vs. reoperation & 0.521 & 0.478 & $>0.999$ \\
\hline NYHA score & 0.078 & 0.248 & 0.210 \\
\hline \multicolumn{4}{|l|}{ Intraoperative } \\
\hline Surgery type ${ }^{d}$ & 0.890 & 0.283 & 0.240 \\
\hline Perioperative Ml & 0.130 & 0.232 & 0.413 \\
\hline Perfusion time & $<0.001$ & 0.018 & 0.045 \\
\hline Cross clamp time & 0.002 & 0.006 & 0.509 \\
\hline \multicolumn{4}{|l|}{ Postoperative } \\
\hline Deep sternal infection & - & $>0.999$ & - \\
\hline Stroke & - & 0.392 & - \\
\hline Bleeding requiring reoperation & - & $>0.999$ & - \\
\hline Atrial fibrillation & - & $>0.999$ & - \\
\hline Pneumonia & - & $>0.999$ & - \\
\hline Ventilation >48 h & - & 0.002 & - \\
\hline Renal failure & - & 0.587 & - \\
\hline Ventilation time & - & 0.026 & - \\
\hline Total ICU stay & - & 0.002 & - \\
\hline Length of hospital stay & - & 0.001 & - \\
\hline ICU readmission & - & $>0.999$ & - \\
\hline
\end{tabular}

NYHA New York Heart Association, MI myocardial infarction, ICU intensive care unit

${ }^{a}$ All mid-term deaths were more than 30 days following the operation

${ }^{\text {b }}$ Surgeries from 2001-2006 were compared to those from 2007-2012; the former time period was the reference category emergent vs.

elective procedures

cEmergent vs. elective procedures

${ }^{d}$ Surgeries including coronary artery bypass grafts (CABGs) were compared to those that did not

operability are often difficult, as research has shown that XCL time is an independent predictor of mortality and morbidity in patients undergoing cardiac surgeries $[1,2$, 4]. Our results demonstrate that while high in relation to less complex surgeries, a $12.4 \%$ mortality in these complex, high risk patients is lower than that reported by studies in the literature addressing longer XCL times. Nissinen et al. observed a $31.5 \%$ 30-day mortality rate 
Table 5 Univariate analysis of pre-, intra-, and postoperative variables with respect to 30-day postoperative complications $(n=202)$

\begin{tabular}{lc}
\hline Variable & $p$-value \\
\hline Era & 0.852 \\
Preoperative & \\
Gender & 0.248 \\
Status & 0.285 \\
Angina & 0.477 \\
NYHA Score & 0.613 \\
Diabetes & 0.450 \\
First operation vs. reoperation & 0.381 \\
Smoker & 0.877 \\
Patient age & 0.731 \\
Perioperative & \\
Perfusion time & 0.003 \\
Cross clamp time & 0.040 \\
Postoperative & \\
Length of hospital stay & $<0.001$ \\
Total ICU stay & $<0.001$ \\
Ventilation $>48$ h & $<0.001$ \\
\hline
\end{tabular}

NYHA New York Heart Association, ICU intensive care unit

in their patients with XCL times greater than $240 \mathrm{~min}$ [2]. Furthermore, Al-Sarraf et al. found that high risk patients (EuroScore $\geq 6$ ) with XCL times $>90 \mathrm{~min}$ and those with XCL times $<60 \mathrm{~min}$ and $\leq 90 \mathrm{~min}$ were respectively 4.7 and 3.1 times more likely to die than those with XCL times $\leq 60 \mathrm{~min}$ [1]. Doenst et al. found that XCL times greater than $30 \mathrm{~min}$ were associated with a steadily increasing rate of mortality [4].

Our results differ slightly from the above findings. In our cohort, perfusion time was significantly associated with all deaths, mid-term deaths and operative deaths by univariate analysis, while XCL time was associated with all deaths and mid-term deaths only. Both perfusion time and XCL time were significantly associated with 30-day complications by univariate analysis. Neither perfusion time nor XCL time was significantly associated with mortality or complications by multivariate analysis, although XCL time was associated with mid-term mortality with $p=0.081$ under Cox proportional hazards analysis. Studies have shown that modern methods of myocardial protection have greatly reduced the mortality expected from long XCL times. Bezon et al. showed an absence of increased mortality and morbidity during prolonged cross-clamping with continuous retrograde tepid cardioplegia with systemic normothermia [7]. Furthermore, Bar-el et al. found no increase in mortality in operations requiring more than two hours of cross-clamp time with the use of antegrade administration of warm, undiluted blood and continuous retrograde infusion of tepid, undiluted blood with added potassium and magnesium [10]. Myocardial protection is extremely important and a standardized approach was utilized with cardioplegia delivered every 15 min during cross-clamping. Septal temperatures were monitored and kept under $10^{\circ}$ Celsius. Right ventricular protection via grafts to the right side and integrated into the cardioplegia circuit is used if there is disease. Antegrade cardioplegia in the root or ostial right perfusion is used if there is no disease, with the addition of ice on the right ventricle surface.

CPB duration has been shown to be positively correlated with interleukin-6 response that is responsible for the systemic inflammatory response (SIR) associated with adverse outcomes in cardiac surgery [8]. SIR is multifactorial in cause, but evidence suggests that blood-to-artificial surface contact leads to platelet activation and results in an altered platelet shape. This altered shape activates cascades producing coagulants, complement and inflammatory cytokines like IL-6 [8]. Furthermore, studies such as that by Wan et al. showed increasing levels of Il-6, Il-8, and Il-10 with longer ischemic times [13]. Thus with extremely long cross clamp times there is a possibility of increased inflammatory mediators which can lead to increased incidence of complications through the SIR. Heparin coated circuits and the

Table 6 Logistic regression analysis of independent variables with respect to 30-day mortality and complications ${ }^{a}$

\begin{tabular}{lllll}
\hline & 30-day Mortality & & 30-day Complications \\
\hline Variable & OR $(95 \% \mathrm{Cl})$ & $p$-value & OR (95 \% Cl) & 0. -value \\
Patient age & $1.02(0.98-1.07)$ & 0.305 & $1.00(0.97-1.03)$ & 0.902 \\
Gender $^{b}$ & $2.44(1.004-5.93)$ & 0.049 & $1.19(0.62-2.31)$ & 0.599 \\
Perfusion time & $1.01(1.00-1.01)$ & 0.113 & $1.01(1.00-1.01)$ & 0.139 \\
Cross clamp time & $0.99(0.98-1.01)$ & 0.362 & $1.00(0.99-1.01)$ & 0.968 \\
Surgery type $^{c}$ & $0.64(0.24-1.71)$ & 0.377 & $0.53(0.25-1.12)$ & 0.097 \\
Era $^{d}$ & $1.17(0.48-2.83)$ & 0.725 & $0.90(0.50-1.63)$ & 0.726 \\
\hline
\end{tabular}

ICU intensive care unit

${ }^{a}$ All mortalities for this analysis occurred perioperatively

${ }^{\mathrm{b}}$ The reference category was males

'Surgeries including coronary artery bypass grafts (CABGs) were compared to those that did not; the reference category was surgeries involving CABG

${ }^{d}$ Surgeries from 2001-2006 were compared to those from 2007-2012; the former time period was the reference category 
Table 7 Cox proportional hazards regression analysis of independent variables with respect to the mid-term mortality ${ }^{\text {a }}$

\begin{tabular}{llc}
\hline Variable & OR $(95 \% \mathrm{Cl})$ & $p$-value \\
\hline Gender $^{\mathrm{b}}$ & $2.11(1.13-3.94)$ & 0.020 \\
Perfusion time & $1.00(0.99-1.01)$ & 0.933 \\
Cross clamp time $^{c}$ & $1.01(0.999-1.02)$ & 0.081 \\
Surgery type $^{c}$ & $1.44(0.65-3.22)$ & 0.372 \\
Era $^{\mathrm{d}}$ & $1.06(0.53-2.13)$ & 0.861 \\
Age & $1.04(1.004-1.07)$ & 0.027 \\
Ventilation $^{2}$ 48 h & $2.72(1.46-5.08)$ & 0.002
\end{tabular}

${ }^{a}$ All mortalities occurred more than 30 days after the surgical procedure ${ }^{\mathrm{b}}$ The reference category was males

'Surgeries including coronary artery bypass grafts (CABGs) were compared to those that did not; the reference category was surgeries involving CABG ${ }^{d}$ Surgeries from 2001-2006 were compared to those from 2007-2012; the former time period was the reference category

avoidance of cardiotomy suction has been used as a possible means to decrease inflammatory mediators and thus SIR.

A number of studies have reported the correlation between prolonged XCL and bypass time and renal compromise $[1,3,6,11]$. This acute kidney injury is multifactorial and related to preoperative renal function as well as intraoperative factors such as hypoperfusion, emboli, and medications. Taniguchi et al. showed that when CPB times exceed $90 \mathrm{~min}$, the chance of renal dysfunction, an independent risk factor for mortality, increased significantly [14]. In 2003 Boldt et al. measured urinary proteins excreted and found that with bypass times greater than $90 \mathrm{~min}$ these markers of renal injury were elevated and remained so compared to those without these times [15]. In our cohort, renal failure was classified as an increase in creatinine of 3.0 times over baseline or as any patients requiring dialysis. While renal failure was not significantly

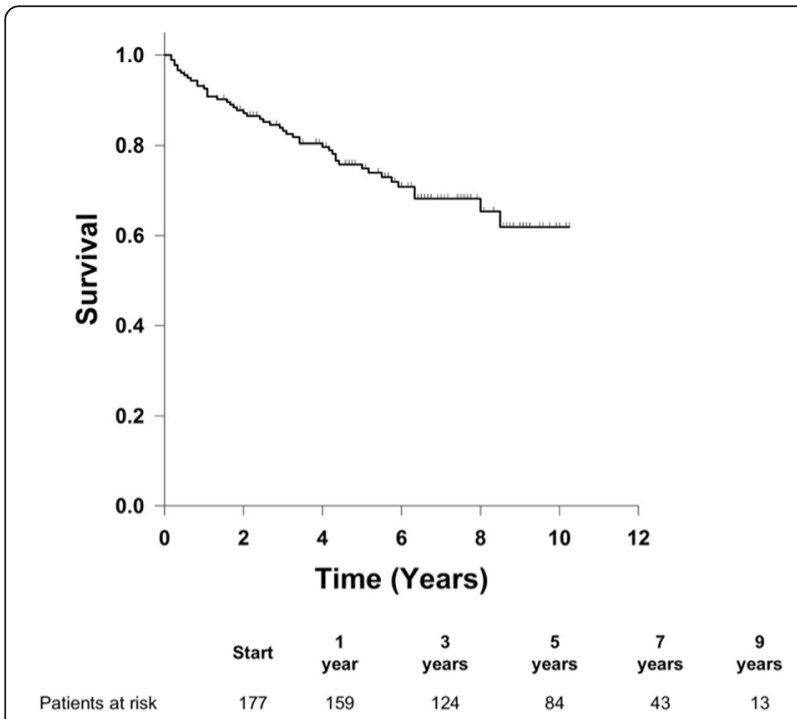

Fig. 1 Kaplan-Meier survival curve predicting survival of patients associated with mortality by univariate analysis, a relatively large number $(10.4 \%)$ of patients experienced renal failure. A review by Rosner and Okuza showed that mortality in patients requiring dialysis after cardiac surgery was uniformly high in fifteen studies, at an average of 60$70 \%$ [24]. Therefore, optimization of preoperative renal function by delaying surgery until all effects from dye administration are gone, discontinuing nephrotoxic medications and renal consultation in these patients is crucial. Intraoperative management by avoiding hypotension and severe hemodilution can be utilized to mediate renal complications [16].

Prolonged postoperative ventilation $(>48 \mathrm{~h}$ ) was significantly associated with both 30-day and mid-term mortality in our cohort under univariate analysis. A high incidence of pneumonia, prolonged ventilation and other pulmonary complications have been shown in prior literature $[1,3,12]$. For example, Al-Sarraf et al. showed that XCL times greater than or equal to $90 \mathrm{~min}$ put a patient at 1.6 times the risk of pulmonary complications compared to patients with a shorter ischemic time [1]. One study suggests that this is likely a result of increased vascular resistance in the lungs, and the accumulation of anaerobic metabolic byproducts in blood flowing through the pulmonary circuit following declamping in addition to a postoperative increase in membrane permeability with subsequent pulmonary edema causing further complications [9]. It has been suggested that the decrease in arterial oxygen tension and other pulmonary imbalances due to heparin use are caused by perioperative pulmonary microemboli [17]. Leukocyte depletion filters and a reduced use of the cardiotomy suction device can both be utilized to reduce postoperative pulmonary complications [18].

A high incidence of stroke has been shown to occur with prolonged XCL [1]. A 2000 study demonstrated that longer durations of bypass were associated with increased embolic load on the brain [19]. A moderate incidence of stroke was observed in this study (4.0\%), although this is consistent with other studies in the literature $[1,5]$. Although the correlation between the incidence of stroke and mortality did not reach statistical significance in our study, of the $4.0 \%$ who suffered a stroke, $75 \%(6 / 8)$ died within thirty days of the procedure, as compared to $12.4 \%$ of the entire cohort. A cohort with a higher number of patients may demonstrate a statistically significant relationship with the incidence of postoperative stroke and mortality. Although previous research has reported a high incidence of complications such as renal failure and stroke with prolonged XCL, the correlations between these complications and XCL time in these studies was not assessed $[1,5,11]$. In the past ten years, routine preoperative CT scanning of the thoracic aorta as well as intraoperative epiaortic echocardiography and cerebral oximetry have been utilized to attempt to reduce the incidence of stroke. 
Multiple studies have suggested that female gender is associated with increased mortality and morbidity [20-22]. In our cohort, female gender was significantly correlated with mid-term mortality by Cox proportional hazards analysis, and was significantly associated with 30-day mortality by logistic regression. Our results also demonstrated a 2.44 times higher 30-day mortality and a 2.11 times higher midterm mortality in females who underwent operations requiring prolonged cross clamp times. Blankenstein et al. demonstrated double the operative mortality in women who underwent CABG surgery [20]. Abramov et al. also showed an increase in early mortality in women $(2.7 \%)$ vs. men $(1.8 \%)$ after CABG surgery [21]. There are many possible explanations for this increased operative mortality. Abramov et al. suggest that women have significantly increased incidences of preoperative risk factors such as diabetes, hypertension, peripheral vascular disease, congestive heart failure, urgent operation and angina class 3 or 4 relative to men [21]. Similarly, Tran et al. suggest that women have more complex morphology due to underdiagnosis of valve disease, and a general underestimation of the severity of cardiac illness in females [22]. Finally, Blankenstein et al. suggest that the lower BSA of females relative to males acts as a surrogate for smaller coronary vessel size, which may lead to reduced graft patency and negatively influence mid-term survival. The same study found that when mortality is risk adjusted for this higher prevalence of preoperative complications and lower BSA, females still have $22 \%$ higher operative mortality than males [20].

Despite the above risk factors and postoperative complications, patients who survived thirty days postoperatively and were discharged from the hospital had excellent midterm survival. One, three, five and seven year survival in our cohort was $91.9 \%, 83.2 \%, 75.6 \%$ and $65.7 \%$ respectively. The era in which the surgery took place was not significantly associated with complications or mortality by multivariate analysis.

These data demonstrate that the prognoses for complex surgeries with extended XCL times are reasonable and that it may be reasonable to offer surgery to very complex patients who may have been refused in the past. Optimization of patients prior to undergoing these complex procedures is vital for improving outcomes. Waiting 5-7 days after a catheterization or CT angiogram minimizes any potential of nephrotoxicity in elective cases. Holding anticoagulants can minimize the deleterious effect of blood transfusions, and maximizing cardiac medications such as beta-blockers and blood pressure medication may benefit patients. Surgeries involving patients with high HgA1c levels should be delayed until said levels are controlled. Finally, from a lifestyle perspective, insisting that patients stop smoking and requiring patients to be ambulatory as soon as possible (with the goal of achieving twenty minutes of continuous activity) may also enhance beneficial outcomes.
Limitations to this study include it being a retrospective review of prospective data. For mid-term data, only survival was monitored and we were not able to assess quality of life. There is also no ability to assess why cross clamp time was so long as operative notes were absent or incomplete and we were unable to discern all problems encountered, however we excluded patients who needed to have the cross clamp applied a second time to attempt to minimize this. Another possible limitation to this study is the small sample size $(n=202)$. Finally, the study is limited in its design as a single institution study over a long period of time. However, after stratifying patients by time, we found that era is not a statistically significant predictor of mortality or postoperative complications.

\section{Conclusion}

In conclusion, there is significant but acceptable shortterm mortality and morbidity in this cohort of complex patients. There is also excellent mid-term survival in patients who survive the initial operation. Female gender was significantly associated with both 30-day mortality and mid-term mortality by multivariate analysis. Patient age and prolonged postoperative ventilation were significantly associated with mid-term mortality by cox proportional hazards analysis. There are few studies that look at midterm survival in patients undergoing these surgeries, and our findings demonstrate a need for further longitudinal studies in these patients. Future studies should focus on preoperative optimization of these patients in terms of respiratory function and renal function. Postoperative care also needs to be studied and optimized, which we believe incorporates a multidisciplinary team approach to these complex patients.

\section{Abbreviations \\ XCL, cross-clamp; CPB, cardiopulmonary bypass; STS, Society of Thoracic Surgeons; SD, standard deviation; CABG, coronary artery bypass graft; $\mathrm{MI}$, myocardial infarction; NYHA, New York Heart Association; ICU, Intensive Care Unit; SIR, systemic inflammatory response; IABP, intra-aortic balloon pump; IMA, inferior mesenteric artery}

\section{Acknowledgements}

Not applicable.

\section{Funding}

Not applicable.

\section{Availability of data and material}

The data sets supporting the conclusions of this article are available upon request to Dr. Hooker (email: drbobhooker@gmail.com) pending IRB approval.

\section{Authors' Contributions}

BS designed the study, helped to carry out statistical analysis and data collection, and drafted the manuscript. TT was involved in data collection and helped to draft the manuscript. AD helped to design the study, carried out statistical analysis and helped to draft the manuscript. JH was involved in data collection. EM was involved in data collection. CW was involved in data collection. $\mathrm{RH}$ conceived of the study, was involved in data collection and 
participated in drafting the manuscript. All authors read and approved the final manuscript.

\section{Competing Interests}

The authors declare that they have no competing interests.

\section{Consent for publication}

Not applicable.

\section{Ethics approval and consent to participate}

This study was reviewed and approved by the Spectrum Health Institutional Review Board and consent was waived due the retrospective nature of the study.

\section{Author details}

'Department of Thoracic and Cardiovascular Surgery, Spectrum Health, Fred and Lena Meijer Heart and Vascular Institute, 100 Michigan St. NE, 49503 Grand Rapids, MI, USA. Grand Rapids Medical Education Partners, 945 Ottawa Ave NW, Grand Rapids, MI 49503, USA. ${ }^{2}$ Department of Surgery, Michigan State University, 15 Michigan St. NE, Grand Rapids, MI 49503, USA

${ }^{4} 123$ York Street Apt. \#22V, New Haven, CT 06511, USA.

Received: 7 January 2016 Accepted: 5 July 2016

Published online: 12 July 2016

References

1. Al-Sarraf N, Thalib L, Hughes A, Houlihan M, Tolan M, Young V, et al. Cross-clamp time is an independent predictor of mortality and morbidity in low- and high-risk cardiac patients. Int J Surg. 2011;9:104-9.

2. Nissinen J, Biancari F, Wistbacka J, Peltola T, Loponen P, Tarkiainen P, et al. Safe time limits of aortic cross-clamping and cardiopulmonary bypass in adult cardiac surgery. Perfusion. 2009;24(5):297-305.

3. Durandy $Y$, Younes M, Mahut B. Pediatric warm open heart surgery and prolonged cross-clamp time. Ann Thorac Surg. 2008;86:1941-7.

4. Doenst $\mathrm{T}$, Borger M, Weisel R, Yau T, Maganti M, Rao V. Relation between aortic cross-clamp time and mortality - not as straightforward as expected. Eur J Cardiothorac Surg. 2008:33:660-5.

5. Safi H, Winnerkvist A, Miller C, lliopoulos D, Reardon M, Espada R, et al. Effect of extended cross-clamp time during thoracoabdominal aortic aneurysm repair. Ann Thorac Surg. 1998;66:1204-9.

6. Oyama M, McNamara J, Suehiro G, Suehiro A, Sue-ako K. The effects of thoracic aortic cross-clamping and declamping on visceral organ blood flow. Ann Surg. 1983;197(4):459-63.

7. Bezon E, Choplain J, Khalifa A, Numa H, Salley N, Barra J. Continuous retrograde blood cardioplegia ensures prolonged aortic cross-clamping time without increasing the operative risk. Interactive Cardiovas Thorac Surg. 2006:5:403-7.

8. Whitten C, Hill G, Ivy R, Greilich P, Lipton J. Does the duration of cardiopulmonary bypass or aortic cross-clamp, in the absence of blood and/or blood product administration, influence the IL-6 response to cardiac surgery? Anesth Analg. 1998;86:28-33.

9. Simon G. The pathophysiology of aortic cross-clamping and unclamping Anesthesiology. 1995;82(4):1026-57.

10. Bar-El Y, Adler Z, Kophit A, Kertzman V, Sawaed S, Ross A, et al. Myocardial protection in operations requiring more than $2 \mathrm{~h}$ of aortic cross-clamping. Eur J Cardiothorac Surg. 1999;15:271-5.

11. Bucerius J, Gummert J, Borger M, Walther T, Doll N, Onnasch J, et al. Stroke after cardiac surger: a risk factor analysis of 16,184 consecutive adult patients. Ann Thorac Surg. 2003:75:472-8.

12. Onorati F, De Feo M, Mastrorberto P, Cristodoro L, Pezzo F, Renzulli A, et al. Determinants and prognosis of myocardial damage after coronary artery bypass grafting. Ann Thorac Surg. 2005;79(3):837-45.

13. Wan S, LeClerc JL, Vincent JL. Cytokine Responses to Cardiopulmonary Bypass: Lessons Learned From Cardiac Transplantation. Ann Thorac Surg. 1997;63(1):269-76

14. Parreiras VC, Rocha IS, Martins AS, Meira EBS, Taniguchi FP. Influence of fresh frozen plasma as a trigger factor for kidney dysfunction in cardiovascular surgery. Rev Bras Cir Cardiovasc. 2012;27(3):405-10.

15. Boldt J, Brenner T, Lehmann A, Suttner S, Kumle B, Isgro F. Is kidney function altered by the duration of cardiopulmonary bypass? Ann Thorac surg. 2003;75:906-12.
16. Karkouti K, Beattie WS, Wijeysundera DN, Rao V, Chan C, Dattilo KM, Djaiani $\mathrm{G}$, et al. Hemodilution during cardiopulmonary bypass is an independent risk factor for acute renal failure in adult cardiac surgery. J Thorac Cardiovasc Surg. 2005;129(2):391-400.

17. Bowald S, Eriksson I, Wiklund L. The influence of heparin on haemodynamics and blood gases during abdominal aortic surgery. Acta Chir Scand. 1980;146(5):333-41.

18. Apostolakis EE, Koletsis EN, Baikoussis NG, Siminelakis SN, Papadopoulos GS. Strategies to prevent intraoperative lung injury during cardiopulmonary bypass. J Cardiothorac Surg 2010;5(1). Web.

19. Brown WR, Moody DM, Challa VR, Stump DA, Hammon JW. Longer duration of cardiopulmonary bypass is associated with greater numbers of cerebral microemboli. Stroke. 2000:31(3):707-13.

20. Blankenstein R, Ward RP, Arnsdorf M, Jones B, Lou Y, Pine M. Female gender is an independent predictor of operative mortality after coronary artery bypass graft surgery: contemporary analysis of 31 Midwestern hospitals. Circulation. 2005:112(9 Suppl):1323-327.

21. Abramov D, Tamariz MG, Sever JY, Christakis GT, Bhatnagar G, Heenan AL, et al. The influence of gender on the outcome of coronary artery bypass surgery. Ann Thorac Surg. 2000;70:800-6.

22. Tran A, Ruel M, Chan V. Gender differences in outcomes following cardiac surgery: implications for managing patients with mitral valve disease. Curr Opin Cardiol. 2015;30(2):151-4.

23. "Social Security Death Index." Geneology Bank. N.p., n.d. Web. 10 July 2012.

24. Rosner A, Okusa M. Acute Kidney Injury Associated with Cardiac Surgery. Clin J Am Soc Nephrol. 2006;1:19-32.

\section{Submit your next manuscript to BioMed Central and we will help you at every step:}

- We accept pre-submission inquiries

- Our selector tool helps you to find the most relevant journal

- We provide round the clock customer support

- Convenient online submission

- Thorough peer review

- Inclusion in PubMed and all major indexing services

- Maximum visibility for your research

Submit your manuscript at www.biomedcentral.com/submit 